\title{
Using postal questionnaires to identify carer depression prior to initial patient contact
}

\section{AIMS AND METHOD}

To assess whether postal questionnaires, used as a local initiative, were useful in identifying carer depression allowing early support for community-dwelling carers of older adults with mental health needs. The Geriatric Depression Scale and a questionnaire collecting information on the carer's circumstances were sent to carers of consecutive patients routinely referred to a community mental health team for older adults in south London. Rates of carer depression between postal questionnaire responders and non-responders were compared.

\section{RESULTS}

The response rate to the postal questionnaires (33\%) was similar to that observed in other postal studies;

\begin{abstract}
$42 \%$ of responders had depression compared with only $4.6 \%$ of nonresponders.
\end{abstract}

\section{CLINICAL IMPLICATIONS}

Pre-contact postal questionnaires may present a simple method of enhancing early detection of carer depression for minimal economic outlay.
Caring for an elderly individual with a disability is stressful. It can contribute to physical and psychiatric morbidity in family carers ${ }^{1-3}$ and also increase their mortality. ${ }^{4}$ In particular, high rates of psychiatric morbidity have been observed in carers of people with mental health problems. Most research has been completed with carers of people with dementia; ${ }^{2,5,6}$ it shows those carers have increased rates of stress, distress, psychological illness, depression and anxiety. Research also confirms higher rates of depression in carers of people with other psychiatric disorders. ${ }^{7}$ Carers of older adults with depression have poorer mental health and perceived quality of life than those of older adults who do not have depression. ${ }^{8}$ Carers' psychological well-being is of great importance when considering community care for older adults with mental health needs for two reasons: to prevent and treat psychological and psychiatric morbidity in the carers themselves, and to enable the patient to live in their own home for as long as possible. Carer depression and stress predicts entry into care homes in older people,, 10 and carer stress is the main social reason for admission to acute psychogeriatric wards and a predictor of increased length of stay. ${ }^{11}$ Viewing carers as part of the primary care population, screening for depression can improve carers' outcomes compared with usual care, ${ }^{12}$ particularly when identification is coupled with effective disease management for depression in older adults - reducing depressive symptoms and improving health status. ${ }^{13-15}$

Postal surveys are commonly used in medical research. Response rates for samples from electoral rolls, health authority registers and health service registers range from 21 to $51 \%{ }^{16-18}$ Increasingly, health providers mail service information to patients and carers, which commonly precedes their first contact with services. We set up a project in which we used the routine mailing from our mental health service to help identify carer depression prior to initial contact, with the intention of enabling the early detection of carer psychological distress and thus improving services for carers.

\section{Method}

Consecutive patients routinely referred to a community mental health team for older adults in south London were posted information on local services and trust policy on confidentiality prior to an initial visit by a clinician. As part of this information pack a covering letter, the 15-item Geriatric Depression Scale (GDS) ${ }^{19}$ for the carer and a questionnaire collecting basic information on carer's circumstances were included for family carers to complete and return in an addressed envelope (no postage provided). Following the initial mailing, no prompts to return the forms where made.

Responders completed a carer information sheet which collected information (tick box options) in four areas.

1. Relationship to the patient (son or daughter/ husband or wife/grandson or granddaughter/sister or brother/friend or neighbour/other, please specify).

2. How close they lived to their relative/friend (in the same house/locally/less than 50 miles away/more than 50 miles away).

3. How often they saw their relative (daily/2-4 h per week/4-6 h per week/once a week/fortnightly or less.

4. Whether they had other commitments and responsibilities as well as caring for their friend/ relative and the nature of the commitments (fulltime work/part-time work/children or family/caring for other relatives or friends/other, please specify).

For non-responders this information was collected from the patients' notes. Depression was defined as a GDS score of 5 and above for the responders and by DSM-III-R clinically-based impression in the nonresponders. 
7

original

papers

\section{Results}

Forms were sent to 148 patients. Notes were unavailable for 2 patients (missing data); 97 patients had a regular family carer and 49 did not. Of the 97 family carers, 32 (33\%) completed and returned the carer forms either by post or at the initial visit to the service. The notes of the 65 patients, whose carers did not return the forms, were reviewed for clinical evidence of depression in the carer. This information is routinely available, as clinical staff collect information on the carers' well-being as part of a carer assessment of need. Of the 32 carers who returned the questionnaires, all completed the carer information sheet and 31 completed the GDS.

Details of the responders and non-responders are shown in Table 1. Although there was no statistically significant gender difference between responders and non-responders (Pearson chi-squared $P=0.35$, d.f. $=1$ ), there were statistically significantly greater numbers of wives compared with husbands completing and returning the forms (Pearson chi-squared $P=0.041$, d.f. $=1$ ). There was no statistically significant difference in co-residence of carers with regard to rates of response to the forms (Pearson chi-squared $P=0.47$, d.f. $=1$ ).

When considering the other commitments that carers might have, information was available on all 31 responders but only on 28 non-responders. There was no statistically significant difference in commitments between responders and this subset of non-responders (Pearson chi-squared $P=0.58$, d.f. $=1$ ).

\section{Depression rates in carers}

Of the 31 responders, 13 (42\%) had depression as defined by a GDS score of 5 or above; 3 of the 65 non-responders ( $4.6 \%)$ had depression as defined by
DSM-III-R-based clinical interview. The prevalence of depression in the responder group was significantly higher than in the non-responder group (Mann-Whitney $U$ : responders, mean rank 60.63; non-responders, mean rank 42.72; two-tailed significance $P<0.001$ ).

Comparing carers who had depression with those who did not, the only significant association from the carer information sheet was that significantly more wives than husbands had depression (Pearson chi-squared $P=0.022$, d.f. $=1$.

\section{Discussion}

The aim of this audit was to see whether a simple postal survey of carers, prior to first contact with mental health services for the patient, could help identify carer depression and therefore enable early intervention to maximise carer health for the benefit of the carer and the patient.

\section{Limitations}

It must be acknowledged that this study has limitations. The most important is that carer depression in responders and non-responders was ascertained using different methods. This was because we did not wish to interfere with the normal clinical process except by the addition of the postal questionnaire. We chose the GDS cut-off point of 5 as this is reported to show good correlation to DSM-III-R clinical diagnosis of major and minor depression. ${ }^{20,21}$ The assessments of depression in the non-responders were made by well-qualified clinicians used to administering clinically-based interviews and versed in assessing carers' needs and psychiatric morbidity as part of clinical practice.

Table 1. Characteristics of responders and non-responders

\begin{tabular}{lccc}
\hline & Responders, $n(\%)$ & Non-responders, $n(\%)$ & $\chi^{2}$, Pearson two-sided (d.f.) \\
\hline Relationship to patient & $11(34)$ & $11(17)$ & $0.041(1)$ \\
Wife & $8(25)$ & $26(40)$ & $0.041(1)$ \\
Husband & $6(19)$ & $14(22)$ & \\
Daughter & $2(6)$ & $8(12)$ & \\
Son & & $2(3)$ & \\
Daughter-in-law & $1(3)$ & $1(2)$ & \\
Niece & $1(3)$ & $1(2)$ & $0.35(1)$ \\
Nephew & $1(3)$ & $1(2)$ & $0.35(1)$ \\
Sister & $2(6)$ & & \\
Grandson & $14(44)$ & $35(54)$ & $0.58(1)$ \\
Friend & $18(56)$ & $30(46)$ & $0.58(1)$ \\
Gender & $9(29)$ & $10(36)$ & $0.47(1)$ \\
Male & $22(71)$ & $18(64)$ & $0.47(1)$ \\
Female & & & \\
Responsibilities & $23(72)$ & $51(78)$ & $14(22)$ \\
Other commitments & $9(28)$ & & \\
No other commitments & & & \\
Living with patient & & & \\
Yes & & & \\
No & & &
\end{tabular}


A further important limitation is the low response rate $(33 \%)$. This is similar to other postal studies but it is clear that there may have been selection bias in the responders. However, it was the purpose of the audit to see whether this response bias would make this method of identifying depression unhelpful in this carer group. The selection bias appeared to work in favour of capturing cases of depression, with those who responded having much higher levels of depression than those who did not. The responder group therefore included much of the population at high risk for depression.

\section{Strengths}

This study provides information on responders and nonresponders in clinical practice in a representative psychiatric population. The results may be generalised to old age psychiatric service users presenting to secondary care and the intervention was simple and required no extra resources.

The rate of depression in our overall group of carers of older adults with psychiatric disorders was $17 \%$, similar to that observed by Livingston et $\mathrm{al}^{7}$ in their community study (24\%). In our overall sample, significantly more female spousal carers had depression compared with male spousal carers, a finding that highlights the vulnerability of this group also observed by other researchers. ${ }^{1,5-7,22,23}$

We found significantly higher rates of depression in responders compared with non-responders (42 v. $5 \%$ ). Responders in this study could be seen as those seeking help for themselves by completing a GDS and this would account for both the significantly higher rates of depression in responders and for similar rates of depression in studies looking at carers seeking help. Our findings correlate well with Gallagher et al's, ${ }^{24}$ who in their study of family caregivers of relatives with dementia found rates of depression of $46 \%$ in those seeking help to increase their coping skills.

Rates of postal response might have been improved by the payment of postal costs back to the unit (Harrison et $\mathrm{al}^{17}$ found the best response rates of $40.5 \%$ where post stamps were provided). None the less, the findings of this study suggest that pre-assessment postal screening of individuals referred to old age mental health services may have a useful part to play in the early identification of depression in carers, at minimal additional cost.

\section{Declaration of interest}

None.

\section{References}

1 Vitaliano PP, Zhang J, Scanlan JM Is caregiving hazardous to one's physical health? A metaanalysis. Psychol Bull 2003; 129 946-72.
2 Schulz R, O'Brien AT, Bookwala J, Fleissner K. Psychiatric and physical morbidity effects of dementia caregiving: prevalence, correlates, and causes. Gerontologist 1995; 35: 771-91.
3 Broe GA, Jorm AF, Creasey H, Casey $B$, Bennett $H$, Cullen J, et al. Carer distress in the general population results from the Sydney Older Persons Study. Age Ageing 1999; 28: 307-11.

4 Schulz R, Beach SR. Caregiving as a risk factor for mortality. JAMA 1999; 282: 2215-9.

5 Mahoney R, Regan C, Katona C, Livingston G. Anxiety and depression in family caregivers of people with Alzheimer disease: the LASER-AD Study. Am I Geriatr Psychiatry 2005; 13: 795-801.

6 Schulz R, Martire LM. Family caregiving of persons with dementia: prevalence, health effects and support strategies. Am J Geriatr Psychiatry 2004; 12 $240-9$.

7 Livingston G, Manela M, Katona C. Depression and other psychiatric morbidity in carers of elderly people living at home. BMJ 1996; 312: 152-6.

8 Sewitch MJ, McCusker J, Dendukur $\mathrm{N}$, Yaffe MJ. Depression in frail elders: impact on family caregivers. Int J Geriatr Psychiatry 2004; 19 : 655-65.

9 Nobili A, Riva E, Tettamanti M, Lucca U, Liscio M, Petrucci B, et al. The effect of a structured intervention on caregivers of patients with dementia and problem behaviors: a randomized controlled pilot study. Alzheimer Dis Assoc Disord 2004; 18: $75-82$.

10 AraiY, Sugiura M, Washio M, Miura H, Kudo K. Caregiver depression predicts early discontinuation of care for disabled elderly at home. Psychiatry Clin Neurosci 2001; 55 379-82.

11 Draper B, Luscombe G. Quantification of factors contributing to length of stay in an acute psychogeriatric ward. Int J Geriatr Psychiatry 1998; 13: 1-7.

12 Pignone MP, Gaynes BN, RushtonJL, Burchell CM, Orleans CT, Mulrow $C D$, et al. Screening for depression in adults: a summary of the evidence for the U.S. Preventive ServicesTask Force. Ann Intern Med 2002: 136: 765-76.

13 Banerjee S, Shamash K, Macdonald AJD, Mann AH. Randomised controlled trial of effect of intervention by psychogeriatric team on depression in frail elderly people at home. BMJ 1996; 313: 1058-61.

14 Ciechanowski P, Wagner E, Schmaling K, Schwartz S,
Williams B, Diehr P, et al. Community-integrated homebased depression treatment in older adults: a randomized controlled trial. JAMA 2004; 291 . 1569-77.

15 Gallo JJ, Bogner HR, Morales KH, Post EP, LinJY, Bruce ML. The effect of a primary care practice-based depression intervention on mortality in older adults: a randomized trial. Ann Intern Med 2007; 146: 689-98.

16 Harrison RA, Cock D. Increasing response to a postal survey of sedentary patients: a randomised controlled trial. BMC Health Serv Res 2004; 4: 31

17 Harrison RA, Holt D, Elton PJ. Do postage stamps increase response rates to postal surveys? A randomized controlled trial. Int J Epidemiol 2002; 31 872-4.

18 Campbell MJ,WatersWE. Does anonymity increase response rate in postal questionnaire surveys about sensitive subjects? A randomized trial. J Epidemiol Community Health 1990; 44: 75-6.

19 Shiekh JL, Yesavage JA. Geriatric Depression Scale (GDS): recent evidence and development of a shorter form. Clin Gerontol 1986; 5: $165-73$.

20 Gerety MB, Williams JW Jr, Mulrow CD, CornellJE, Kadri AA, Rosenberg $J$, et al. Performance of case-finding tools for depression in the nursing home: influence of clinical and functional characteristics and selection of optimal threshold scores. J Am Geriatr Soc 1994; 4: 1103-9.

21 Jongenelis K, Pot AM, Eisses AMH, Gerritsen DL, Derksen M, Beekman ATF, et al. Diagnostic accuracy of the original 30 -item and shortened versions of the Geriatric Depression Scale in nursing home patients. Int J Geriatr Psychiatry 2005; 20 . 1067-74.

22 Miller B, Cafasso L. Gender differences in caregiving: fact or artifact? Gerontolologist 1992; 32 498-507.

23 Yee JL, Schulz R. Gender differences in psychiatric morbidity among family caregivers: a review and analysis. Gerontologist 2000; 40 147-64.

24 Gallagher D, Rose J, Rivera P, Lovett S, Thompson LW. Prevalence of depression in family caregivers. Gerontologist 1989; 29: $449-56$

*Candida R. Graham Academic Physician, Northern Medical Program, 3333 University Way, Prince George, British Columbia, Canada V2N 4Z9, email: cgraham@unbc.ca, Sube Banerjee Professor of Mental Health and Ageing, The David Goldberg Centre, Institute of Psychiatry, London, UK， Randeep S. Gill Research Coordinator, TheWolfson Centre for Age-Related Diseases, King's College London, London, UK

original papers

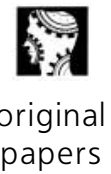

.

